\title{
EĞiTiM ÇALIŞANLARINDA UYKU KALITESI VE TÜKENMIŞLIK SENDROMU
}

\author{
Z. Merey, M. Boysan**, C. Ateş ${ }^{\star \star \star}$
}

\section{ÖZET:}

Amaç: İş ortamı ve uyku kalitesi ilişkisini ele alan araştırmaların sayısı her geçen gün artmaktadır. Bu çalışmada mesleki ve demografik özellikler de dikkate alındığında uyku kalitesinin tükenmişlik düzeyleriyle ne ölçüde ilişkili olduğu araştırılmıştır. Yöntem: Van Merkezde ilköğretim okullarında çalışmakta olan 198 öğretmene demografik soru formu, Maslach Tükenmişlik Ölçeği ve Pittsburgh Uyku Kalitesi İndeksi uygulanmıştır. Uyku kalitesiyle mesleki ve kişisel özelliklerin tükenmişlik düzeylerine etkisi regresyon ağacı kullanılarak analiz edilmiştir. Bulgular: Öznel uyku kalitesinin tükenmişliğin stresle ilişkili alt faktörleri olan Duyarsızlaşma ve Duygusal Tükenme ile önemli düzeyde ilişkili olduğu bulunmuştur. Kişisel Başarı'nın daha çok mesleki özelliklerle ilişkili olduğu görülmüştür. Sonuç: Öznel uyku kalitesi tükenmişlik düzeylerindeki artışta önemli rol oynamaktadır. Uy-

Arş. Gör., Yüzüncü Yıl Üniversitesi, Eğitim Fakültesi.

** Arş. Gör., Yüzüncü Yıl Üniversitesi, Fen-Edebiyat Fakültesi, Psikoloji Bölümü.

*** Arş. Gör., Ankara Üniversitesi, Tıp Fakültesi, Biyoisatistik Bölümü. ku kalitesini artırıcı önlemlerin alınması, çalışanların iş kalitesinin artmasına ve ruh sağlığının korunmasına katkıda bulunacaktır.

Anahtar Kelimeler: Uyku kalitesi, tükenmişlik sendromu, eğitim çalışanları

\section{Sleep Quality and Burnout Syndrome Among Teaching Staff}

\section{ABSTRACT}

Objective: The studies that address risk factors of burnout syndrome make more emphasize on sleep quality as well as occupational characteristics. The aim was to assess influence of sleep quality on occupants' burnout syndrome as occupational and demographical characteristics were taken into account. Method: Demographical questionnaire, Maslach Burnout Inventory and Pittsburgh Sleep Quality Index were administered among 198 teachers working in Van Centrum. Relations between occupational and demographical characteristics, sleep quality, and burnout syndrome were analyzed using regression trees. Results: Subjective sleep quality was substantially associated to Emotional Exhaustion and Depersonalization in 
which both represent stress related dimensions of burnout syndrome. Personal Accomplishment was predicted by occupational characteristics. Conclusion: Sleep quality plays an important role on elevations of burnout scores. Interventions in order to improve occupants' sleep quality will contribute to their work quality and prevent their psychological health.

Key Words: Sleep quality, burn out syndrome, teaching staff

\section{GIRIŞ VE AMAÇ}

İşyerindeki ortamın sağlık üzerindeki önemli etkilerini konu alan çok sayıda bilimsel çalışma bulunmaktadır. Araştırmalar işteki sıkıntıların uyku bozukluğu, psikolojik problemler, somatizasyon ve sağlık durumundaki bozulmalara neden olan önemli bir risk faktörü olduğunu ortaya koymaktadır (Nasermoaddeli ve ark 2002, Landbergis 1998, Demiral ve ark 2006; Bosma ve ark 1998).

İşteki tükenmişlik, iş yerindeki süreğen duygusal ve kişiler arası olumsuz koşulların neden olduğu stresler karşısında kişilerin uzamış psikolojik tepkisi olarak tanımlanmaktadır (Maslach 2003). Tükenme özel yaşamda ve iş yaşamında önemli sorunları birlikte getirebilmektedir. Tükenme düzeyindeki artış psikosomatik bozukluklara, evlilik ve aile yaşantısında bozulmalara, uyku bozukluğu, alkol ve madde kullanımında artışa neden olmaktadır (Arslan ve ark 1996, Çam 1992, Ergin 1992).Tükenmişlik büyük önem taşıyan bir kavram olmasına karşın açık ve tek bir şekilde yapılan bir tanımlamayla ifade edilmesinde güçlükler bulunmaktadır. Yapılan çalışmalarda kavram, genellikle kullanılan ölçme aracının ele aldığı biçimiyle kullanılmaktadır. Bunun yanı sıra, tükenmişlik kavramı pek çok boyutu içinde barındırmaktadır. Yapılan çalışmalar tükenmişlikle ilişkili olarak beş boyutun varlığını göstermektedir. Bunlar, genel tükenmişlik (bezmişlik, yorgunluk, vs.), zihinsel tükenmişlik, motivasyonsuzluk veya işlevsellikte düşme, fiziksel tükenmişlik ve uykuda bozulma (Watt ve ark 2000, Dalakas 1998). Tükenmişlik kavramı genellikle söz konusu boyutlar içinde ilk üç boyutla temsil edilmektedir. Buna karşın, tükenmişlikle ilgili çalışmalarda fiziksel tükenmişlik ve uykudaki bozulma göz ardı edilmektedir (Maslach ve ark 1992).

Tükenmişlik durumu, genellikle, kişilerin maruz kaldıkları uzun süreli stres durumlarında gözlenmektedir (Lewis ve Wessely 1992). İşyerindeki çalışma ortamında yaşanan kişiler arası uyumsuzluk, düşük sosyal destek ve ağır iş yükü tükenmişliğe sebep olan risk faktörlerinin başında gelmektedir (Hardy ve ark 1997, Bültmann ve ark 2002, Demerouti ve ark 2001). Aynı zamanda yüksek psikolojik beklentiler, sınırlandırılmış karar alma yetkisi ve uykudaki bozulmalarla birleşerek işle ilişkili sorunların artışına etki ettiği gözlenmiştir (Theorell ve ark 1988). Uyku problemlerinin tükenmeyle arasındaki ilişkiyi ortaya koyan çalışmaların sayısında son yıllarda bir artış gözlenmektedir. Geniş örneklemli kesitsel çalışmalar, uyku kalitesi ve tükenmişlik arasındaki güçlü ilişkiye işaret etmektedir (Åkerstedt ve ark 2002, Åkerstedt ve ark 2004). Yine vardiyalı çalışmanın sirkadyen ritimdeki bozulmalarla birlikte çalışanlarda tükenmişliğe neden olduğu bildirilmektedir (Åkerstedt ve Landstrom 1998, Shen ve ark 2006).

Sucuoğlu ve Kuloğlu (1996) özel eğitim veren öğretmenlerde tükenmişliğin mesleki zorluklarla ilişkili olduğunu göstermektedir. Ankara'da 1462 öğretmenin katıldığı bir çalışmada tükenmişliğin çalışma süresi ile negatif yönde ilişkili olduğu, üstlerle olumlu ilişkilerin ve çalışanların mesleklerinin verimliliğine ve geleceğine ilişkin olumlu değerlendirmelerinin ise çaIışanları tükenmeden koruduğunu göstermektedir (Dolunay ve Piyal 2003). Yurtdışında yapılan bir çalışma İngiltere'deki ilk ve orta öğretimde görev yapan öğretmenlerin uyku kalitesiyle işteki problemleri büyütme ve işyeri sorunları arasında yakın ilişkinin varlığını bildirmektedir (Cropley ve ark 2006). 
$\mathrm{Bu}$ çalışmada Van Merkez ilköğretim okullarında görev yapmakta olan öğretmenlerin uyku kalitesi, mesleki ve kişisel özelliklerinin tükenmişlikle olan ilişkisi araştırılmıştır.

\section{YÖNTEM VE GEREÇLER}

\section{Örneklem}

Araştırmanın örneklemini Van Merkezde çalışmakta olan 82' si (\%41.41) branş ve 116'sı (\%58.59) sınıf öğretmeni olmak üzere toplam 198 öğretmen oluşturmuştur. Çalışmanın örneklemine dahil edilen öğretmenler, 2007-2008 öğretim yılında Van Merkezde bulunan ilköğretim okullarında görev yapmakta olan öğretmenler arasından gelișigüzel örnekleme metoduyla seçilmiştir. Araştırmaya katılanların büyük çoğunluğunun evli (\%75.76) olduğu gözlenmiştir. Çalışmaya katılmayı kabul edenlerin büyük çoğunluğunu erkekler (67.68\%) oluşturmaktadır. Örneklemin yaş ortalaması 33.61 ve standart sapması 7.335'dir.

\section{Veri Toplama Araçları}

\section{Anket Formu}

Çalışmaya katılanların yaş, cinsiyet, medeni durumlarının yanı sıra; sınıf ve branş öğretmenlerinin oranını belirleyebilmek için sorulan alan sorusu, haftalık çalışma saati, meslekteki çalışma süresiyle ilişkili bilgilerin araştırıldığı bir anket hazırlanmıştır. Aynı formda öğretmenlerden mesleki işlevsellikleriyle ilişkili olarak, 'Mesleğinizi ne kadar işlevsel buluyorsunuz?' sorusunun 0 (hiç) ve 4 (tam anlamıyla işlevsel) arasında bir ölçek üzerinde değerlendirmesi istendi.

\section{Maslach Tükenmişlik Ölçeği (MTÖ)}

Ölçek her birinde beşli likert tipi ölçüm yapan 22 sorudan oluşmaktadır. Duygusal Tükenmişlik, Kişisel Başarı, Duyarsızlaşma olmak üzere üç alt boyutu vardır. Cronbach alpha değerleri Duygusal Tükenmişlik alt ölçeği için 0.90, Kişisel Başarı alt ölçeği için 0.71 ve Duyarsızlaşma alt ölçeği için 0.79 olarak bildirilmiştir (Maslach ve Jackson 1986). Duygusal
Tükenmişlik ve Duyarsızlaşma boyutları olumsuz ve Kişisel Başarı boyutu ise olumlu yanıtları içermektedir. Türkiye'de geçerlik ve güvenirlik çalışması Çam (1992) tarafından yapıımıştır.

\section{Pittsburgh Uyku Kalitesi Indeksi (PUKi)}

Her bir öğretmenin son bir ay içindeki uyku kalitesini belirlemek için konuyla ilişkili en yaygın kullanıma sahip ölçme aracı olan Pittsburgh Uyku Kalitesi İndeksi (PUKi) kullanıldı. Bireyde öznel uyku kalitesini, uyku miktarını, uyku bozukluğunun varlığını ve şiddetini değerlendirmemizi sağlayan ve 19 soru içeren PUKi, Buysse ve arkadaşları (1989) tarafından geliştirilmiştir. Ölçeğin iç tutarlılığı 0,83 ve 28 günlük test tekrar test güvenirliği $r=0,85$ olarak bildirilmiş̧ir. İndeks öznel uyku kalitesi, uyku gecikmesi, uyku süresi, uyku verimliliği, uyku bozukluğu, uyku ilacı kullanımı ve gündüz işlerinde bozulmanın değerlendirildiği yedi öğeden oluşmaktadır. Her bir indeksin yanıtı belirti sıklığına göre 0-3 arasında puanlanmaktadır. Puanlama, geçen ay boyunca hiç olmamışsa 0 , haftada birden az ise 1 , haftada bir veya iki kez ise 2, haftada üç veya daha fazla ise 3 olarak yapılmaktadır. Elde edilen yüksek değerler uyku kalitesinin kötü, uyku bozukluğu seviyesinin yüksek olduğunu göstermektedir. Ölçeğin uyku bozukluklarının belirlenmesinde tanısal duyarlılığı \%89.6, özgüllüğü $\% 86.5$ 'tir (Buysse ve ark 1989, Buysse ve ark 1991). PUKI'nin Türkçe formunun uyarlaması Ağargün ve arkadaşları (1996) tarafından yapılmıştır.

\section{işlem}

Katılımcılara anket, Maslach Tükenmişlik Ölçeği (MTÖ) ve Pittsburgh Uyku Kalitesi İndeksi (PUKI) birlikte verilmiştir. Van Merkezde ilköğretim okullarında çalışmakta olan öğretmenlere uygulamalar bireysel olarak yapılmıştır. Koşullara bağlı olarak bazı katılımcılar anketleri evde doldurduktan sonra araştırmacılara teslim etmiştir. Katılımcıların her birinden yapılan uygulamanın sonuçlarının yayınlanabileceğine dair yazılı izin alınmıştır. 
Araştırmada elde edilen verilerin değerlendirilmesinde tanımlayıcı istatistikler ve regresyon ağacı analizi kullanıımıştır.

\section{BULGULAR}

Araştırmaya katılan öğretmenlerin haftalık çalışma saatinin medyanı 30 saat, en az çalışan 8 saat ve en çok çalışan 60 saat çalıştığını bildirmiştir. Meslekteki ortalama çalışma süresi 10.17 yıldır (ss=7.470). 0 ve 4 arasındaki bir ölçekte değişen mesleğin işlevselliğine ilişkin inanç düzeyi ortalama 2.63'tür $(s s=0.838)$. Yapılan üç regresyon ağacı analizinde bağımlı değişkenler olarak, sırasıyla, tükenmişliğin alt boyutları olan Duygusal Tükenmişlik, Duyarsızlaşma ve Kişisel Başarı değişkenleri alınmıştır. Yaş, cinsiyet, medeni durum, haftalık çalışma saati, meslekteki çalışma süresi, mesleğin işlevselliğine ilişkin inanç düzeyiyle mesleki alan ve Pittsburgh Uyku Kalitesi İndeksi' den elde edilen 7 alt indeksin puanları her üç analizde de bağımsız değişkenler olarak modele alınmıştır.

Bağımsız değişkenlerin Duygusal Tükenmişlikle ilişkisinin değerlendirildiği regresyon ağacında, öznel uyku kalitesi'nin istatistiksel olarak önemli düzeyde bağımlı değişkene etki ettiği görülmektedir. Yapılan analiz sonucunda öznel uyku kalitesinin Duygusal Tükenmişlik' le olan ilişkisine göre katılımcılar iki alt grupta sınıflandırılmıştır. Öznel uyku kalitesi indeksinden 1 ve altında alan 125 kişinin ortalama Duygusal Tükenmişlik puanlarıyla bu indeksten 1'in üzeride alan 73 kişinin Duygusal Tükenmișlik puanları arasındaki fark önemli bulunmuştur. Düşük uyku kalitesi bildiren grubun Duygusal Tükenmişlik puanları diğer gruba göre önemli düzeyde yüksektir $(F(1,196 ; p<0.05)$.

Duyarsızlaşma alt ölçeğinin bağımlı değişken olduğu regresyon ağacı analizi sonucunda, öznel uyku kalitesi dışında diğer bağımsız değişkenlerin etkisi önemli bulunmadığından dolayı modele alınmamıştır. Analizde öznel uyku kalitesinin Duyarsızlaşmayla olan ilişkisine göre örneklem üç alt grupta sınıflandırılmıştır. Gruplar arasındaki Duyarsızlaşma alt ölçe- ğinden alınan puanlara göre varyanslar arasındaki farkın önemli olduğu anlaşılmaktadır $(F(2,195)=9.249, p<0.05)$. Öznel uyku kalitesindeki düşme Duyarsızlaşma düzeylerinde artışla sonuçlanmaktadır.

Analiz sonucunda Kişisel Başarı alt ölçeğinden alınan puanların mesleki işlevselliğe ilişkin inanç ve mesleki çalışma süresiyle ilişkili olduğu bulunmuştur. 0 ve 4 arasında puanlanan mesleki işlevsellik soruna 3 ve üzerinde yanıt veren 120 kişinin, 2 ve altında yanıt veren 78 kişiye göre Kişisel Başarı puanları önemli düzeyde yüksektir $(F(1,196)=14.348, p<0.05)$. Mesleki işlevsellik düzeyi bakımından üst gruptakilerden dokuz yıl ve altında görev yapmış olanların ( $n=66)$, bu grupta dokuz yılın üstünde çalışanlara $(n=54)$ göre Kişisel Başarı puanlarının daha düşük olduğu görülmüştür $(F(1$, 118) $=8.404, p<0.05)$.

\section{TARTIŞMA VE SONUÇ}

Öğretmenlerle yapılan bu çalışmada demografik özellikler dikkate alındığında, tükenmişlik düzeyleri bakımından cinsiyetler arasında önemli bir fark olmadığı bulunmuştur. Yaş değişkeninin de tükenmişlikle ilişkili alt boyutlarda tükenmeye etki eden önemli bir faktör olmadığı görülmektedir. Elde edilen sonuçlar ülkemizde yapılmış olan çalışmalarla tutarlılık taşımaktadır (Sucuoğlu ve Kuloğlu 1996, Haran ve ark 1998). Bununla birlikte dünya genelinde yapılan pek çok araştırma sonucunda tükenmişlik düzeylerinin erken yaşlarda daha fazla olduğu; ancak cinsiyetin tükenme üzerinde etkili bir faktör olmadığı bildirilmektedir (Maslach ve ark 2001). Çalışmaya katılan öğretmenlerin büyük çoğunluğu evli olduğunu belirtmiştir (\%75.26). Öğretmenler arasında medeni duruma göre tükenme düzeyleri bakımından önemli bir farka rastlanmamıştır.

Karasek ve Theorell (1990) çalışanların iş ortamıyla ilişkili sıkıntılarının genellikle şu iki unsurla yakından ilişkili olduğunu belirtmektedir: işin gerekleri ve çalışanların işle ilişkili talepleri karşılayabileceklerine ilişkin inancı. Bu durumda 
Duygusal
Tükenmişlik

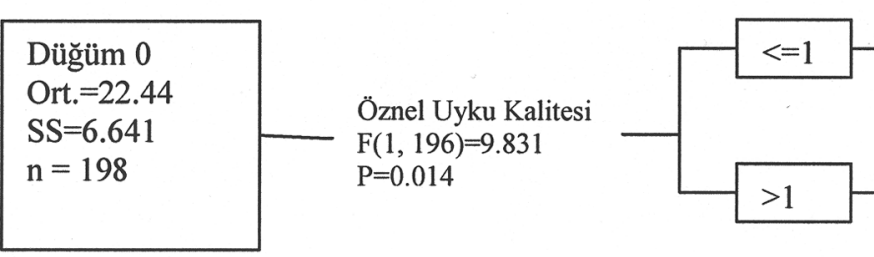

Düğüm 1

Ort. $=21.33$

$\mathrm{SS}=6.172$

$\mathrm{n}=125$

$\% 63.1$

Düğüm 2

Ort. $=24.33$

$\mathrm{SS}=7.022$

$\mathrm{n}=73$

$\% 36.9$

Şekil 1. Uyku Kalitesi ve Demografik Değişkenlerin Duygusal Tükenmişlik ile İlişkisi.

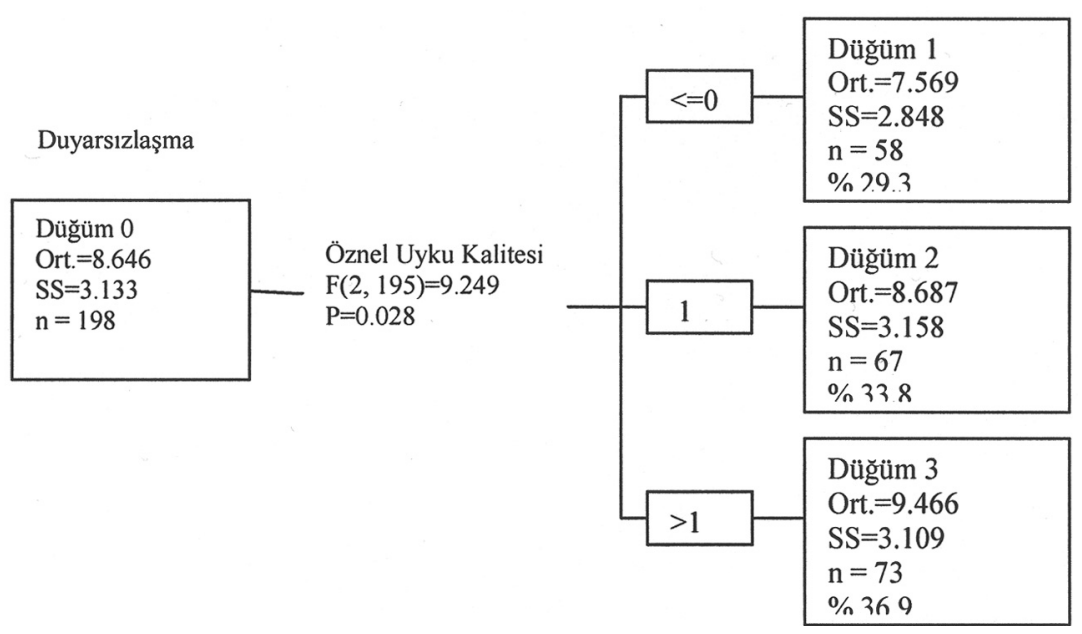

Şekil 2. Uyku Kalitesi ve Demografik Değişkenlerin Duyarsızlaşma ile İlişkisi.

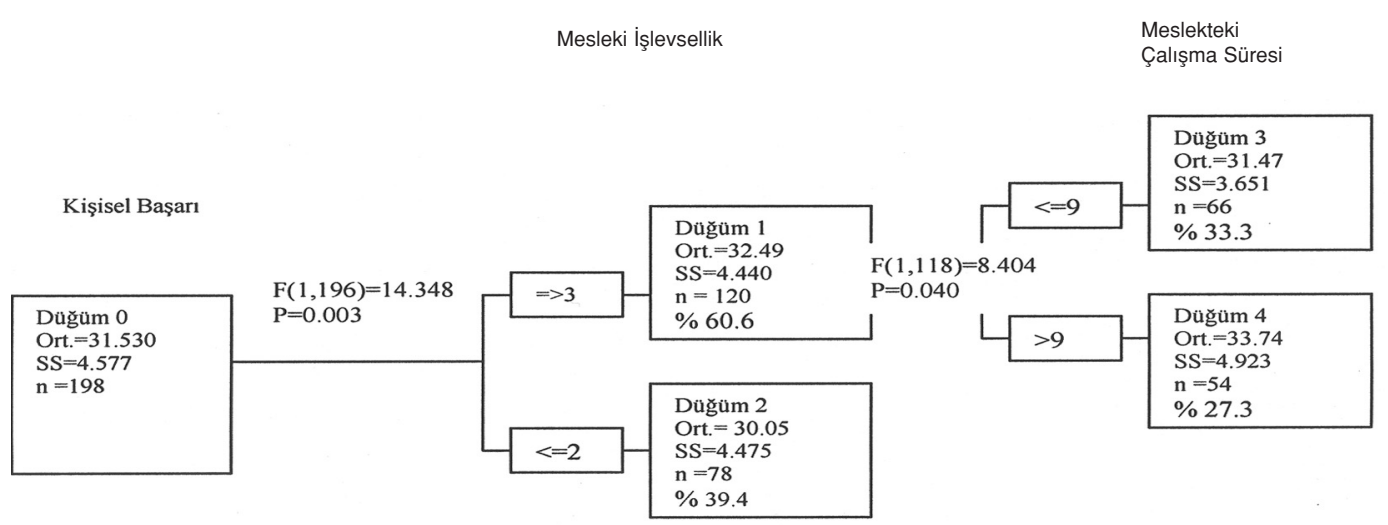

Şekil 3. Uyku Kalitesi ve Demografik Değişkenlerin Kişisel Başarı ile Ilişkisi. 
çalışanların işin gereklerinin üstesinden geldiğine ilişkin inancı iş yaşamında dengeleyici bir rol oynamaktadır. Yine uzun çalışma süresi ve ağır iş yükünün çalışanlarda tükenmeye sebep olduğunu gösteren araştırmalar bulunmaktadır (Hardy ve ark 1997, Bültmann ve ark 2002). Uzun çalışma saatleri uyku düzeninde bozulmalara sebep olmaktadır (Kalimo ve ark 2000). Bu çalışmada öğretmenlerin haftalık çalışma saatleri iş yükünü gösteren bir değişken olarak çaıışmaya alındı. Haftalık çalışma saatinin 8 ve 60 arasında değiştiğini bildiren ve büyük çoğunluğu ortalama 30 saat çalışan öğretmenlerin tükenmişlik alt ölçekleriyle çalışma saati arasında önemli bir ilişki bulunamamıştır. Sınıf öğretmeni veya branş öğretmeni olarak çalışıyor olmak arasında da tükenmişlik düzeyleri bakımından önemli bir farka rastlanmamıştır.

Sonuçlar tükenmişlik kavramının alt faktörlerinden biri olan kişisel başarıyla mesleğin işlevselliğine ilişkin inanç düzeyi ve meslekteki çalışma süresinin önemli düzeyde ilişkili olduğunu göstermektedir. Araştırma örnekleminin kişisel başarı değişkeni bakımından sınıflandıııması sonucunda büyük çoğunluğun işlevsel bir meslekte çalıştığına inandığı ortaya çıkmıştır $(n=120, \% 60.6)$. Mesleki işlevsellik bakımından üst grupta yer alan çalışanların kişisel olarak başarılı olduklarını düşünenler olduğu görülmektedir. Bu gruptakilerin kişisel başarı puanları alt grupta yer alan katılımcılara oranla önemli düzeyde yüksek bulunmuştur $(p<0.01)$. Mesleğini işlevsel olarak tanımlayan gruptakilerden meslekte dokuz yılın üzerinde çalışmış olanların, meslekte dokuz yıl ve altında çalışanlara göre kendilerini kişisel olarak daha başarılı değerlendirme eğiliminde oldukları anlaşılmaktadır $(p<0.05)$. Bu durum mesleğini işlevsel ve kişisel başarılarını yüksek algılayanların meslekte daha uzun süre kalma eğiliminde olduklarının da bir göstergesi olduğu biçiminde yorumlanabilir.

Uyku bozukluğu pek çok psikolojik problemin altında yatan önemli bir etkendir (Demir ve Mercan 2007). İş ortamındaki problemlerin ve tükenmişliğin uykudaki bozulmaların ortaya çıkışında önemli rol oynadığını gösteren araştırmaların sayısı artmaktadır (Landbergis 1998, Cropley ve ark 2006, Nasermoaddeli ve ark 2002). Uyku kalitesi ve tükenmişlik arasındaki ilişki karşılıklı bir etkileşimi içermektedir. Uyku kalitesindeki bozulmaların tükenmişliğe yol açıı̆ını gösteren çalışmaların sayısı da gittikçe artmaktadır. Uyku kalitesiyle birlikte ele alınan kişisel ve mesleki özellikler dikkate alındığında, öznel uyku kalitesinin tükenmişlik boyutlarından Duygusal Tükenme ve Duyarsızlaşma düzeylerinin en önemli belirleyicisi olduğunu ortaya koymaktadır. Duygusal tükenmişlik bakımından iki grupta kümelenen örneklemde, DT puanları yüksek olan 73 kişinin öznel uyku kalitesinin önemli ölçüde kötü olduğu görülmüştür. Bir diğer tükenmişlik alt faktörü Duyarsızlaşma düzeylerinin en önemli belirleyicisi olan öznel uyku kalitesi bakımından, Duyarsızlaşma alt ölçeğine göre sınıflandırılan üç grup arasındaki farkların önemli olduğu bulunmuştur. Uyku kalitesi düştükçe işteki duyarsızlaşma artış göstermektedir $(p<0.05)$. Elde edilen sonuçlar daha önce yapılan çalışmaların sonuçlarıyla uyumludur.

Öğretmenlerin tükenmişlik düzeyleriyle ilişkili yapılan çalışmaların sonuçları yaş faktörü ve öğretmenlerin eğitim verme yükümlülüğü taşıdıkları öğrenci kitlesinin özelliklerinin tükenmişlik düzeyleriyle yakından ilişkili olduğunu göstermiştir. Yine eğitim çalışanları arasında rol çatışması, rol belirsizliği, karar verme süreçlerine katılımda eksiklik, ödüllendirme sistemi ve otonomi gibi örgütsel özelliklerin tükenmişlikle ilişkili olduğunu bildiren çalışmalar bulunmaktadır (Cordes ve Dougherty 1993, Maslach ve ark. 2001). Eğitim çalışanlarının tükenmişlik düzeylerine etki edebilecek diğer risk faktörlerinin bu çalışma kapsamında ele alınamamış olması bu çalışmanın sınırılıkları arasındadır. Van' da çalışmakta olan öğretmenlerin katıldığı bu araştırmanın sonuçları uyku kalitesinin çalışanların tükenmişlik düzeylerindeki artışın en önemli belirleyicisi olduğu söylenebilir. Tükenmişlik kavramının daha çok stresle ilişkili yanını 
yansıtan Duygusal Tükenmişlik ve Duyarsızlaşma boyutlarındaki artış üzerinde uyku kalitesinin etkisi açıkça görülebilmektedir. Kişisel Başarıyla ilişkili bulunan değişkenlerin ise daha çok mesleki özellikleri yansıttığı sonucu elde edilmiştir. Çalışmanın örnekleminin Van Merkezde yer alan ilköğretim okullarıyla sınırlandırılmış olması da sonuçların genellenebilirliği açısından diğer bir önemli sınırlılıktır. Buna karşın, yapılan araştırmanın sonuçları eğitim çalışanlarında uyku kalitesinin işteki tükenmişlikle ilişkisini gösteren çalışmalar arasında bir ilktir. Bu ilk çalışmanın sonuçları uyku kalitesinin işteki yaşam kalitesiyle yakından ilişkili olduğunu göstermiştir. Uykuyla ilişkili diğer faktörlerin, uyku kalitesi ve işteki tükenmişliğe etkilerinin kapsamlı bir biçimde ele alındığı geniş çaplı çalışmalara intiyaç duyulmaktadır. Uyku kalitesinin yaşam kalitesi ve psikolojik sağlık üzerindeki önemli etkileri de dikkate alınarak, çalışanların uyku hijyeni konusunda bilgilendirilmeleri ve uyku kalitesini artırıcı önlemler alınması önerilmektedir. Özellikle eğitim, güvenlik ve sağlık gibi sosyal hizmet alanlarında görev yapan çalışanların uyku kalitelerini artırıcı programların uygulamaya konulması, çalışanları tükenmişlik sendromuna karşı koruyucu ve verilen hizmetlerin kalitesini artıııcı yönde etki edecektir. 


\section{KAYNAKLAR}

Agargün M Y, Kara H, Anlar O (1996) Pittsburgh Uyku Kalitesi İndeksinin Geçerliği ve Güvenirliği. Türk Psikiyatri Dergisi, 7: 107-115.

Åkerstedt $\mathrm{T}$, Knutsson A, Westerholm $\mathrm{P}$ ve ark (2002) Sleep Disturbances, Work Stress and Work Hours: A Cross-Sectional Study. J Psychosom Res, 53 (3): 741-748.

Åkerstedt $\mathrm{T}$, Knutsson A, Westerholm $\mathrm{P}$ ve ark (2004) Mental Fatigue, Work and Sleep. J Psychosom Res, 57 (5): 427-433.

Åkerstedt T, Landström U (1998) Work Place Countermeasures of Night Shift Fatigue. Int $\mathrm{J}$ Ind Ergonomics, 21 (3-4): 167-178.

Arslan H, Ünal M, Aslan O ve ark (1996) Pratisyen Hekimlerde Tükenme Düzeyleri. Düşünen Adam, 9 (3): 48-52.

Bosma H, Peter R, Siegrist R ve ark (1998) Two Alternative Job Stress Models and the Risk of Coronary Heart Disease. Am J Public Health, 88(1): 68-74.

Buysee DJ, Reynolds CF, Monk TH ve ark (1989) The Pittsburgh Sleep Quality Index: A New Instrument for Psychiatric Practice and Research. Psychiatry Res 28: 193-213.

Buysse DJ, Reynold CF, Monk TH ve ark (1991) Quantification of Subjective Sleep Quality in Healthy Elderly Men and Women Using the Pittsburgh Sleep Quality Index (PSQI). Sleep, 14: 331-338

Bültmann U, Kant IJ, van den Brandt PA ve ark (2002) Psychosocial Work Characteristics As Risk Factors for the Onset of Fatigue and Psychological Distress: Prospective Results from the Maastrich Cohort Study. Psychol Med, 32: 333-345.

Cropley M, Dijk D, Stanley N (2006) Job Strain, Work Rumination, and Sleep in School Teachers Eur J Work Organ Psychol, 15 (2): 181-196.

Cordes CL, \& Dougherty TW (1993) A Review and Integration of Research on Job Burnout. Academy of Management Review, 18, 621-656.

Çam O (1992) Tükenmişlik Envanteri'nin Geçerlik ve Güvenirliğinin Araştırılması. VII. Ulusal Psikoloji Kongresi Bilimsel Çalışmaları, sayfa 155160, Türk Psikologlar Derneği Yayınları, Ankara.
Dalakas MC, Mock V, Hawkins MJ (1998) Fatigue: Definitions, Mechanisms, and Paradigms for Study. Semin Oncol, 25: 48-53.

Demerouti E, Bakker AB, Nachreiner F ve ark (2001) The Job Demands-Resources Model of Burnout. J Appl Psychol, 86: 499-512.

Demiral Y, Soysal A, Bilgin CA ve ark (2006) The Association of Job Strain with Coronary Heart Disease and Metabolic Syndrome in Municipal Workers in Turkey. J Occup Health, 48(5):332-338.

Dolunay AB, Piyal B (2003) Öğretmenlerde Bazı Mesleki Özellikler ve Tükenmişlik. Kriz Dergisi, 11(1): 35-48.

Ergin C (1992) Doktor ve Hemşirelerde Tükenmişlik ve Maslach Tükenmişlik Ölçeği'nin Uyarlanması. VII. Ulusal Psikoloji Kongresi Bilimsel Çalışmaları, sayfa 143-154, Türk Psikologlar Demeği Yayınları, Ankara.

Haran S, Özgüven HD, Ölmez Ş ve ark (1998) Ankara Üniversitesi Tıp Fakültesi Hastaneleri ve Ankara Numune Hastanesinde Çalışan Doktor ve Hemşirelerde Tükenmişlik Düzeyleri. Kriz Dergisi, 6(1): 75-84.

Hardy GE, Shapiro DA, Borrill CS (1997) Fatigue in the Workforce of National Health Service Trusts: Levels of Symptomatology and Links with Minor Psychiatric Disorder, Demographic, Occupational and Work Role Factors. J Psychosom Res, 43, 83-92.

Kalimo R, Tenkanen L, Härmä M ve ark (2000) Job Stress and Sleep Disorders: Findings from the Helsinki Heart Study. Stress Med, 16(2): 65 - 75.

Karasek RA, Theorell T (1990) Healthy Work: Stress, Productivity, and the Reconstruction of Working Life. New York: Basic Books.

Landsbergis PA (1988) Occupational Stress Among Health Care Workers: A Test of the Job Demands Control Model. J Organ Behav, 9: 217-239.

Lewis G, Wessely S (1992) The Epidemiology of Fatigue: More Questions Than Answers. J Epidemiol Comm Health, 46: 92-97

Maslach C (2003) Job Burnout: New Directions in Research and Intervention. Curr Dir Psychol Sci,12 (5), 189-192. 
Maslach C, Jackson SE (1986) Maslach Burnout Inventory Manual 2 Baskı, Consulting Psychologist Press Palo Alto CA

Maslach C, Schaufeli WB, Leiter MP (2001) Job Burnout. Annu Rev Psychol, 52:397-422.

Nasermoaddeli A, Sekine M, Hamanishi S ve ark (2002) Job Strain and Sleep Quality in Japanese Civil Servants with Special Reference to Sense of Coherence. J Occup Health, 44(5): 337-342.

Shen J, Botly LCP, Chung SA ve ark (2006) Fatigue and Shift Work. J Sleep Res, 15 (1): 1-5.
Sucuoğlu B, Kuloğlu N (1996) Özürlü Çocuklarla Çalışan Öğretmenlerde Tükenmişliğin Değerlendirilmesi. Türk Psikoloji Dergisi, 11 (36):44-60.

Theorell T, Perski A, Åkerstedt T ve ark (1988) Changes in Job Strain in Relation to Changes in Physiological State. Scand J Work Environ Health, 14: 189-196.

Watt T, Gronenvold M, Bjorner JB ve ark (2000) Fatigue in the Danish General Population. Influence of Sociodemographic Factors and Disease. J Epidemiol Comm Health, 54: 827-833. 
